\title{
Uma prosa transdisciplinar sobre a alimentação no contexto das ciências sociais: Entrevista com Alex Galeno ${ }^{1}$
}

\author{
Por Viviany Chaves ${ }^{2}$ \\ PPGCS/UFRN: https://orcid.org/0000-0002-9654-7152
}

DOI: https://doi.org/10.21680/1982-1662.2019v2n25ID18337

\section{Apresentação}

Ao afirmamos que a alimentação é um fenômeno biocultural por excelência, reconhecemos a pluralidade de temas complexos que permeiam o campo da alimentação, seja por uma perspectiva nutricional como também simbólica, própria da infinidade de representações incorporadas ao ato de comer. 0 espaço intersticial cuja alimentação se encontra nos obriga a convocar saberes de diversas áreas do conhecimento (sociologia, antropologia, história, psicologia, etnobotânica, biólogos etc), exigindo, assim, compreender os limites dessas disciplinas.

Essa realidade demonstra a necessidade de ampliar as vertentes de cada disciplina e incluir uma perspectiva transdisciplinar, permitindo, assim, deter a fragmentação entre natureza e cultura, entre ser humano biológico e social. Conhecer os limites da ciência nos faz refletir não mais sobre o que estamos buscando, mas onde queremos chegar. Permite, também, repensarmos sobre a formação de sujeitos que julgam o conhecimento como algo estático, inexplorável e fragmentado, sendo incapazes de realizar conexões, tão pouco considerando as experiências vividas ao longo da vida.

Apoiando-se nessa reflexão, podemos considerar que um dos caminhos para compreender as incertezas do mundo e as questões que cercam o paradigma científico contemporâneo, pode ser guiado pela lógica da transdisciplinaridade, atuando de modo outside, ou seja, se deslocando das fronteiras do seu conhecimento específico

\footnotetext{
1 Professor e coordenador do Programa de Pós Graduação em Ciências Sociais. ORCID: https://orcid.org/0000-0001-5103-0339. E-mail: alexgalenno@gmail.com

2 E-mail: vivianymourachaves@hotmail.com
} 
para transitar por outras áreas e, portanto, estabelecer um ponto de encontro entre os saberes, conforme elucida Edgard de Assis Carvalho.

Em um cenário ocupado pelo pragmatismo da ciência, emergem pesquisadores que despertam para a necessidade de contextualizar o fenômeno alimentar e suas interfaces com o campo das Ciências Humanas e Sociais. O professor Alexsandro Galeno Araújo Dantas é uma dessas personalidades acadêmicas que, nos últimos anos, tem realizado orientações de trabalhos de teses e dissertações dedicadas a estudar o fenômeno da alimentação sob o viés sociológico junto ao programa de Pós Graduação em Ciências Sociais da Universidade Federal do Rio Grande do Norte (PPGCS/UFRN).

Atualmente, Alex Galeno é professor e coordenador do Programa de Pós Graduação em Ciências Sociais e Presidente da Cooperativa Cultural Universitária. Graduou-se em Geografia na UFRN, é Mestre em Ciências Sociais pela mesma instituição e Doutor em Ciências Sociais pela Pontifícia Universidade Católica de São Paulo. Tem Pós-Doutorado pela Universidade de São Paulo na área de comunicação.

Ao longo do seu percurso profissional, orientou o trabalho de dissertação Eça de Queiroz e a cozinha burguesa (2012) de Michelle Medeiros, propondo o exercício de pensar a cozinha burguesa por meio da literatura, guiados pelos conceitos de cozinha de Lévi-Strauss e Claude Fischler. Mais tarde, ainda no plano literário, buscou na comensalidade, ou seja, no ator de comer e beber junto, desvendar às mudanças ocorridas no mundo contemporâneo que afetam os hábitos alimentares. Através da obra de Honoré de Balzac, Rebekka Dantas, em sua dissertação de mestrado, buscou compreender a Comensalidade no romance O Pai Goriot (2016). Para ampliar esta perspectiva, Rebekka, em sua tese de doutorado em andamento, continua seus estudos sobre a comensalidade nos espaços de intimidade n'A Comédia humana de Balzac. Migrando das páginas de literatura para as telas das produções televisivas, em 2018, a dissertação intitulada Espetáculo à mesa: ética da alimentação no Masterchef profissionais foi produzida, por mim sob sua orientação, com o objetivo de compreender as ressignificações do comer e do cozinhar nos espetáculos gastronômicos, para pensar numa ética da alimentação inserida no contexto midiático. Mais recentemente, temos a dissertação de Clébio Lima, A literatura famélica em 0 Quinze de Rachel de Queiroz, produzida no presente ano de 2019.

Além das temáticas aqui discutidas, Alex Galeno ficou conhecido pela obra Antonin Artaud, a revolta de um anjo terrível, como produto de sua tese de 
doutorado defendida na PUC de São Paulo. Ele tem experiência nas áreas de Sociologia e Comunicação, atuando principalmente nos seguintes temas: política e cibercultura; cultura e pensamento complexo; literatura e sociedade.

Foi pensando em dialogar sobre sua linha de produção intelectual, principalmente nos trabalhos voltados para o campo da alimentação, buscando compreender sua disposição para este deslocamente epistemológico que conectava sociologia e alimentação, que Alex Galeno concedeu esta entrevista na manhã do dia 5 de abril de 2019, em sua sala no PPGCS da UFRN.

\section{Entrevista}

\section{Viviany Chaves}

No atual contexto da hipermodernidade em que vivemos, o fenômeno alimentar vem sofrendo transformações que têm implicado severamente em problemas alimentares vigentes no mundo inteiro. A busca pela inovação alimentar através da inclusão de novas tecnologias, os discursos na publicidade de alimentos, a exigência do padrão do culto ao corpo esbelto, são exemplos práticos do aumento das incertezas sobre o quê de fato estamos comendo e pra quê comemos. Como você percebe a construção desses discursos na sociedade?

\footnotetext{
Alex Galeno

É um desafio discutir sobre esse tema que é de uma relevância fundamental para a Revista Inter-legere e agradeço a deferência para o diálogo. Primeiramente dizer que esse fenômeno da exacerbação sobre a questão da alimentação, sobre a visibilidade do fenômeno da comida ou da alimentação em si, ou dos atos alimentares, não é algo tão recente nos escritos da literatura.

A exemplo disto, no século XIX Honoré de Balzac, no Tratados dos excitantes modernos, em um dos ensaios que escreveu, discutiu sobre uma fisiologia gastronômica e chamou a atenção para a ideia de uma gastronomia do olho. Ele começou a perceber que os atos alimentares passavam a acompanhar os hábitos de uma certa teatralização do social, principalmente quando o hábito alimentar sai do espaço da casa, espaço privado, e passa a ocupar o espaço público como, por exemplo, os restaurantes e os salões.
} 
Então a alimentação em si começou a ter uma teatralização ou uma espécie de espetacularização também do hábito de comer. Os banquetes da nobreza e depois da burguesia, mais abastadas no século XIX, tomaram conta, antes nos salões, e, depois, nos restaurantes. Balzac chamou isso de uma gastronomia do olho que, portanto, acompanhou essas mudanças da sociedade durante esta época. Assim, podemos dizer que este é um dos primeiros registros do século XIX, mostrando uma modernidade acompanhada de mudança dos hábitos gastronômicos.

Ainda no plano da literatura, há uma referência paradigmática interessante em A Cidade e as Serras de Eça de Queiroz. Destaca-se o personagem Jacinto - que era um burguês clássico e erudito -, em diálogo com Zé Fernando, em uma passagem que demonstra a ideia tecnológica moderna na cozinha. Neste trecho da obra, sobre laranja com éter, é como um exemplo prático da modernidade-líquida do Zygmund Bauman na sociedade contemporânea. Você tinha uma burguesia sintonizada com as mudanças técnicas e os progressos do próprio capitalismo da época, mas também uma burguesia extremamente situada com a ideia do hábito alimentar. Os comensais começam a sair de uma tradição glutônica, talvez mais embrutecida do hábito à mesa, para uma visão mais do gourmet ou da gourmandise pra relembrar a obra a Fisiologia do gosto de Brillat Savarin.

Eu acho que no campo comunicacional, destaca-se, especialmente, o fenômeno dos reality shows voltados para o comer, um fenômeno mundial próprio desse tempo de exacerbação do olhar. Na realidade, o que nós experimentamos no campo comunicacional é próprio da sociedade iconofágica, segundo a expressão do Norval Baitello. Segundo ele, nos transformamos em sujeitos iconofágicos porque comemos imagens diariamente através dos olhos, portanto, alteramos os sentidos sobre aquelas imagens e, sobretudo, em relação aos corpos que comemos com os olhos: nós começamos a excretar imagens de corpos vazios.

Desse modo, se tudo é imagem, não existe corpo, portanto, não existe sujeito. A iconofagia tem uma reprodução muito forte no campo da alimentação. Por exemplo, o Instagram e o Facebook são exatamente representações de dispositivos técnicos que exacerbaram o espetáculo diante da alimentação. Além do Instagram e do Facebook, os reality shows, ou seja, a televisão como espaço que mais atinge a sociedade, é paradigmático disso. Você tem uma relação de jogo e divertimento e ao mesmo tempo um conhecimento sobre a cozinha começa a ser disseminado. 
Outro aspecto presente nesse discurso da sociedade contemporânea é aquele que denomino como uma espécie de gastro-pedagogia. Todo mundo começa a falar e opinar sobre cozinha, sobre o ato de comer. A televisão através, principalmente, dos reality shows, dissemina um conhecimento considerável sobre a cozinha e o ato de preparar o alimento. Isso é interessante, pois mexe até com a cultura masculina, estabelecendo uma relação de gênero sobre isso, colocando o alimento não apenas no espaço da casa, mas também no espaço público, midiático e, portanto, se criando uma outra ideia de cozinha para além dos papéis determinados pelos sexos.

A questão problematizadora, sobretudo nos reality shows, é que se cria um padrão alimentar que não é da ordem cotidiana e real, da mesma forma que o Norval Baitello fala das imagens vazias. Observa-se que se produz uma simulação sobre o alimento e, claro que isso está sintonizado com o mercado publicitário, com a indústria alimentícia etc. Não sei se isso é bom ou ruim, eu acho que a sociedade contemporânea quem exige isso. O problema é que é um duplo movimento de acesso e de negação, pois é uma simulação sobre o que é comer bem. A consequência do ponto de vista do sujeito é que as pessoas começam a fazer um discurso igual sobre o alimento em função das imagens. Os alimentos viraram comida higienizada, tudo muito fabricado e artificializado, onde você tem que aperfeiçoar ao máximo a técnica. E é isso que chamo de uma gastro-paideia ou uma gastro-pedagogia. Assim, todo mundo se transforma em chef ou em técnico sobre gastronomia. 0 excesso de tecnicização higieniza o gosto e a cozinha. Acho que essa é a consequência civilizatória.

\section{Viviany Chaves}

As práticas alimentares são profundamente influenciadas pelos modelos culturais estabelecidos em uma sociedade, assim sendo, estudar a alimentação sob uma ótica cultural pode nos ajudar a problematizar as escolhas alimentares e os comportamentos dos individuo inseridos nos sistemas culturais alimentares. Partindo disso, de que forma as Ciências Sociais podem contribuir para o estudo da alimentação humana?

\section{Alex Galeno}

Um autor clássico que temos trabalhado nas teses e dissertações sobre a 
questão da alimentação é o Claude Lévi-Strauss. Sua ideia da cozinha universal e, portanto, do triângulo culinário são indispensáveis para quem estuda o fenômeno da alimentação. No entanto, é insuficiente para pensar a sociedade só utilizando a ideia da cozinha universal.

Nesse sentido, eu acho que o autor Claude Fischler, sociólogo e estudioso do campo das ciências da complexidade, tem trabalhado com a ideia de sistema cultural alimentar. Do triângulo culinário, a ideia do cru, cozido e o podre como intermediação sobre a passagem da natureza para a cultura é isso que interessa na cozinha universal. A questão é como que acontece, de maneira distinta, essa passagem no preparo do alimento em sociedades diferentes? Como eu transformo o alimento no artificio do fazer na cozinha? E, então, como se dá a distinção dos sistemas alimentares no mundo? Onde cada cultura vai reproduzindo o assado, o ensopado e o defumado de forma diferente? É nisso que está a riqueza dessa concepção de Lévi-Strauss. No campo das Ciências Sociais é um clássico para estudar o fenômeno alimentar. É como estudar a teoria do incesto nas culturas, pois é uma regra universal e se estabelece em toda e qualquer sociedade. Mas há uma distinção, por exemplo, entre os valores sexuais e a própria sexualidade, eu diria que isso também acontece em relação a cozinha, ou seja, o sistema cultural alimentar vai criando distinção e, ao mesmo tempo, uma pluralidade cultural. Significa dizer que a universalidade não homogeneíza formas de como se come. O modo de preparar (técnicas) é que culturalmente constitui um outro sistema e, portanto, um outro tipo de cozinha. Eu acho que é essa distinção que garante a universalidade levistraussiana.

Neste caso, Fischler no campo da sociologia tem complementado a concepção de Lévi-Strauss. A partir do conceito durkheimiano de "anomia", ele criou o neologismo gastro-anomia para refletir sobre o fenômeno contemporâneo da alimentação. Destaca-se, sobretudo, a pesquisa que ele fez em relação aos hábitos alimentares de franceses, alemães, italianos e americanos ${ }^{3}$. Ele se perguntou sobre a alteração na comensalidade, ou seja, no ato de comer juntos. Para o autor, uma sociedade que come menos junto ou coletivamente, tem um maior índice de sobrepeso e obesidade conforme aponta o Guia alimentar da população brasileira de 2014. Sem dúvidas esta é uma contribuição sociológica fundamental, inclusive para

\footnotetext{
${ }^{3}$ FISCHLER, Claude. Comer: alimentação de franceses, outros europeus e americanos. São Paulo: Ed. Senac SP, 2010.
} 
elaboração das políticas públicas no âmbito da saúde pública, já que o problema da obesidade tem consequências diretas no desenvolvimento de doenças crônicas não transmissíveis.

Pensando sobre os trabalhos que tenho orientado, especificamente a tese de Rebekka Dantas, eu acho que umas das contribuições fundamentais das Ciências Sociais é trabalhar a ideia da comensalidade, buscando avaliar que atos são esses ligados à mesa na sociedade contemporânea. Em Esferas III, o filósofo Peter Sloterdijck, ao analisar a ideia de imunologia e o individualismo exacerbado na sociedade contemporânea, ele exemplifica o apartamento. Ele vai dizer, por exemplo, que a vida no apartamento transformou o sujeito no convidado, no comensal e no cozinheiro, simultaneamente, isso porque ele é sozinho e criou esse espaço de si próprio. Portanto, não tem mesa com o outro, pois o hábito à mesa é solitário.

A comensalidade tem uma alteração do ponto de vista das relações sociais. E se intensifica na atualidade com o uso dos novos dispositivos digitais ou comunicacionais. Veja por exemplo a prática do ifood. O ifood é muito sintonizado com a lógica do apartamento. A comida se espacializa e se comercializa pelo ato técnico e pelo hábito sedentário, você está no seu lugar sozinho e metaforicamente com o restaurante e/ou a cozinha em suas mãos. Então o outro, a alteridade, que é um elemento fundamental no campo da comensalidade, vai começando a se deteriorar. É uma mesa sem ninguém e é óbvio que isso tem relação com as alterações das famílias contemporâneas, a forma do trabalho na sociedade e acho que as Ciências Sociais é fundamental para pensar essas coisas.

Outro autor importante que complementa os argumentos de Lévi-Strauss é o Roland Barthes, que não é das Ciências Sociais, mas foi um crítico literário e semiólogo do campo da liguistisca que trouxe contribuições para pensar a cozinha enquanto linguagem. Barthes diz que a alimentação tem uma dimensão simbólica porque os atos alimentares vão produzindo imagens de produção em torno do fenômeno e nisso reside a espetacularização e também teatro social ao redor da comida. Com essa ideia, ele amplia a noção do Lévi-strauss, ou seja, podemos dizer que a comida é signo. Segundo ele, a comida é uma "unidade funcional de uma estrutura de comunicação", por isso que a comensalidade é um fenômeno interessante. À mesa se come para harmonizar, para conversar, mas também para brigar, para emular, para discutir, portanto, não é uma comunidade meramente 
ausente de conflitos. Dessa forma, o comer opera no plano simbólico do Lévi-Strauss, mas também produz uma condição comunicacional que o Roland Barthes chama atenção: a cozinha se constitui num signo. Por isso é um autor fundamental pra ampliar o debate com as Ciências Sociais e a comunicação.

Por último, um autor mais recente que merece destaque como referência nos estudos sobre alimentação é o Jean-Pierre Poulain. Eu diria que ele é um sociólogo mais ensaísta e que tem feito uma crítica forte sobre a ideia do nutricionismo ${ }^{4}$, mostrando a importância de ampliar cognitivamente esse diálogo para pensar os hábitos alimentares para além dessa dimensão (fisiológica) que tem formado nutricionistas para um outro tipo de sociedade que não existe.

\section{Viviany Chaves}

$\mathrm{Na}$ sua opinião, qual a importância de surgirem pesquisadores que despertam para a necessidade de contextualizar o fenômeno alimentar para além do viés biológico?

\section{Alex Galeno}

Acredito que é uma necessidade do presente, independente de qualquer área, é uma necessidade do mercado econômico, cultural e científico que exige um profissional que não tenha apenas um domínio técnico, obviamente da sua área, mas que ele tenha uma capacidade de percepção mais ampla. Portanto, ele tem que construir uma formação transdisciplinar. Acho que esse é um compromisso ético e pedagógico que você tem que ter na sua formação, independente de qualquer área que esteja, porque no mundo o conhecimento não apenas se produz nas universidades ou na escola, se produz, por exemplo, por Youtubers, se produz por novos dispositivos comunicacionais. Então você tem que dialogar com outras referências, não estou falando só de informações, estou falando de outros tipos de conhecimento, novos produtores de conhecimento. Então você tem que se abrir, você tem que estar sintonizado com a reforma do pensamento, ou de uma certa democracia cognitiva, segundo a expressão de Edgar Morin. Nós temos que democratizar a cognição e você democratiza na hora da formação. Portanto, trata-se de um compromisso ético e

\footnotetext{
${ }^{4} \mathrm{~A}$ ideologia do nutricionismo defende a abordagem dos alimentos pelo viés nutricional. $\mathrm{O}$ nutricionismo é o paradigma dominante da Ciência da Nutrição desde o final do século XIX. Seu foco sobre os nutrientes passou a estabelecer uma visão reducionista tanto da comida quanto da saúde.
} 
político combater o reducionismo técnico disciplinar na formação e eu acho que a transdiciplinaridade é central na formação hoje de qualquer profissional.

\section{Viviany Chaves}

Nos últimos anos você tem orientando teses e dissertações ligadas ao tema da alimentação de modo transdisciplinar. Como foi pra você fazer esse movimento de aproximação com outra área de conhecimento? Como surgiu esse interesse?

\section{Alex Galeno}

$\mathrm{Na}$ realidade eu estava pensando que tem duas coisas que pode responder essa pergunta: primeiro de uma ordem mais inconsciente e outra do acaso, objetiva. Pelo inconsciente, pela trajetória de vida, eu fui um cara que teve muita interdição em relação ao alimento. Não que eu tenha vindo de uma família famélica, mas vim de uma região onde vivi muita situação de seca, em que o problema da falta de água era algo muito sério e até vivenciei os americanos entregando comida na minha pequena cidade Rodolfo Fernandes, localizada no interior do Rio Grande do Norte. Minha mãe era uma professora primária e meu pai foi uma pessoa que trabalhava como vigia na escola, mesmo que fosse originário de uma família abastada de fazendeiro ou de uma aristocracia falida cearense. Lembro-me que como estudante do colégio Atheneu em Natal, quando li, pela primeira vez Vidas Secas, foi um dos livros que leio e releio e que me marcou profundamente. Acho que até me ajudou a compreender psicanaliticamente a interdição na residência universitária durante minha adolescência.

Acho que no plano da formação, calhou o acaso de o primeiro trabalho que orientei foi a dissertação de Michelle Medeiros, pelo viés literário. A única ideia geral que tinha em relação ao tema era essa situação anterior, isto é, do alimento na minha vida ou o tema da fome na literatura. E, então, chegamos a uma ideia de pesquisa que foi muito bem sucedida, digamos assim, que era explorar nas Ciências Sociais a noção de cozinha burguesa produzida pela literatura de Eça de Queiroz em $A$ Cidade e as Serras.

A partir disso, orientei Viviany Chaves, Clébio Lima e Rebekka Dantas. A última tem pesquisado na sua tese, o tema da comensalidade através da obra da Comédia Humana de Balzac. Rebekka que, inicialmente, na dissertação, estudou a comunidade 
comensal no romance $O$ Pai Goriot em Balzac, partindo de uma comunidade com 12 comensais que era a pensão da Madame Vauquet do romance. O Pai Goriot era um grande produtor comerciante de massas que as filhas, quase como uma tragédia shakersperiana, o transforma num sujeito falido e, assim, ele vai morar na pensão para elas manterem a aparência de família tradicional burguesa em Paris. Então, ali você tem a problemática da fome, tem o hábito alimentar, tem as questões éticas e morais que passam naquela comunidade e tudo acontece em torno da mesa.

Outro tema de trabalho orientado foi a dissertação de Viviany em relação ao fenômeno da comunicação e a dimensão ética do que é e o que produz um programa como Masterchef perante o fenômeno de espetáculo ao redor da comida, sendo este um trabalho mais paradigmático. Já a dissertação de Clébio Lima traz mais uma vez a temática da fome na obra $O$ quinze da Rachel de Queiroz, a partir de uma literatura famélica.

Assim, tenho tido uma experiência muito importante como pesquisador a partir desse exercício transdisciplinar. A literatura e a ciência como conexão muito forte e, ao mesmo tempo, pessoas que tem um domínio importante no campo da pesquisa. Outro lado rico é a contribuição dos orientandos para o campo das Ciências Sociais porque chegam com a experiência de iniciação científica, de como fazer pesquisa e também de se abrirem para esse exercício transdisciplinar.

\section{Viviany Chaves}

Gostaria que você falasse um pouco sobre as pesquisas de sob sua orientação. A maioria delas se propôs a pensar as questões sócio-culturais da alimentação pela via da literatura. Assim sendo, como a literatura pode ser utilizada como fonte de estudos para compreensão de fenômenos alimentares? Como você vê essa relação?

\footnotetext{
Alex Galeno

Pensando em Edgar Morin em A Cabeça bem Feita, ele diz que a literatura é como antenas para o mundo. Ele cita, por exemplo, o Balzac que, mais que os cientistas, percebeu a complexidade do humano, principalmente na sociedade do século XIX. Por isso, que o Balzac era tão importante e tão paradigmático para Marx e para Engels.
}

Se você pega o romance Os camponeses, na troca de comunicação de cartas 
entre Marx e Engels, a luta de classes, por exemplo, é muito em função dessa experiência antecipada por Balzac. A literatura permite pensar na condição humana e é isso que Morin destaca, além de gerar uma ciência mais ensaística. Adorno vai dizer que o ensaio é aquilo que amplia o ponto cego da ciência. Então, a literatura e a arte pode ampliar uma outra possibilidade, uma outra cosmovisão que a ciência não daria.

Praticar esse exercício literário faz com que se produzam dissertações e teses ensaísticas com rigor e transdisciplinares. Honoré de Balzac tem sido muito interessante na minha experiência de orientação com mestrandos e doutorandos. 0 Kafka, eu acho que é paradigmático e eu o uso alguns contos como 0 artista da fome, por exemplo. Então, acho que a literatura permite a ampliação de pensar a complexidade do humano a partir de um exercício transdisciplinar.

\section{Viviany Chaves}

Observa-se que cada vez mais o Programa de Pós graduação em Ciências Sociais tem recebido profissionais de diversas áreas de conhecimento. Como você, enquanto professor e coordenador do programa, avalia a articulação e transição entre uma área e outra?

\section{Alex Galeno}

Bom, esse ano nosso programa completa 40 anos. Foi um programa que nasceu com uma vocação transdisciplinar. Foi um programa que incubou outras iniciativas de pós-graduação no próprio CCHLA, tais como: Geografia, Antropologia, Políticas Públicas, História e Comunicação. Você também tinha profissionais aqui de outras áreas como da Saúde Coletiva, por exemplo. Então, o programa tem essa trajetória transdisciplinar. E é isso que tentamos fazer hoje, isto é, manter essa dimensão de não tirá-lo dessa perspectiva mais ampla. Este é um compromisso político e ético de pensar a reforma do pensamento. Como coordenador atual e como professor, tento fazer o possível para que as pessoas se animem com o Programa e com uma formação mais ampla. Eu sempre digo o seguinte para os alunos: transitem entre as áreas, transitem entre os professores, transitem entre os textos e façam uma formação mais ampla, uma formação mestiça, como diz Michel Serres, quer dizer quanto mais mestiço, mais competente para olhar tua área de formação inicial. Então é essa ideia que tenho como coordenador e como professor do programa. 
INTER-LEGERE | Vol. 2, n. 25/2019: c18337| ISSN 1982-1662

Recebido: 28 abri 2019

Aceito: 10 jun 2019 